\title{
A subset of morphologically distinct mammary myoepithelial cells lacks corresponding immunophenotypic markers
}

\author{
Roy R Zhang, Yan-Gao Man, Russell Vang, Jeffrey S Saenger, Ross Barner, Darren T Wheeler, \\ Chang Y Liang, Tuyethoa N Vinh and Gary L Bratthauer
}

Department of Gynecologic and Breast Pathology, Armed Forces Institute of Pathology, Washington, DC, USA

Corresponding author: Yan-Gao Man (e-mail: man@afip.osd.mil)

Received: 6 Jun 2003 Revisions requested: 30 Jun 2003 Revisions received: 4 Jul 2003 Accepted: 7 Jul 2003 Published: 24 Jul 2003

Breast Cancer Res 2003, 5:R151-R156 (DOI 10.1186/bcr635)

(c) 2003 Zhang et al., licensee BioMed Central Ltd (Print ISSN 1465-5411; Online ISSN 1465-542X). This is an Open Access article: verbatim copying and redistribution of this article are permitted in all media for any purpose, provided this notice is preserved along with the article's original URL.

\begin{abstract}
Introduction: Immunostaining for smooth muscle actin (SMA) is commonly used to elucidate mammary myoepithelial (ME) cells, whose presence or absence is a reliable criterion for differentiating in situ and invasive carcinomas. However, some morphologically distinct ME cells fail to stain for SMA. This study intended to assess whether these SMA-negative cells also lack the expression of other ME cell markers.

Methods: Hematoxylin/eosin and SMA immunostained sections from 175 breast cancer patients were examined. Three cases were found to harbor ducts that showed morphologically distinct ME cell layers, but showed no SMA immunostaining in at least one-third of the layer or the entire layer. Eight additional consecutive sections from each case were stained for SMA, using a black chromogen, and each was then re-stained for one of eight additional markers supposed to exclusively or preferentially stain ME cells, using a red

chromogen. SMA-negative ME cells were re-examined for the expression of other markers.

Results: SMA-negative ME cells in two cases also failed to display immunoreactivity for other markers, including calponin, CD10, smooth muscle myosin heavy chain, protease inhibitor 5 (maspin), Wilms' tumor-1, and cytokeratins 5, 14, and 17 (CK5, CK14, and CK17). However, in one case SMA-negative ME cells displayed immunoreactivities for maspin, CK5, CK14, and CK17. The distribution of these ME cells is independent of ductal size, length, and architecture.

Conclusions: A subset of morphologically identifiable ME cells lack the expression of nine corresponding immunophenotypic markers, suggesting that ME cells might also be subject to different normal and pathological alterations.
\end{abstract}

Keywords: double immunohistochemical staining; myoepithelial cell layer; myoepithelial cell markers; myoepithelial-epithelial cell interaction

\section{Introduction}

The epithelial component of normal and non-invasive breast tissues is normally surrounded by a layer of myoepithelial (ME) cells, whose absence or disruption is an absolute prerequisite for tumor invasion and metastasis [1]. ME cells are not easily identifiable in hematoxylin/eosin (H\&E)stained breast tissue sections, as they are often indistinguishable from subjacent myofibroblastic cells in the stroma. Immunohistochemical staining for smooth muscle actin (SMA) has been routinely used to assist in the identification of ME cells [2]. However, we and others have repeatedly noted that about $4-6 \%$ of morphologically rec- ognizable ME cells in H\&E-stained sections fail to display SMA immunoreactivity $[3,4]$. We attempted to assess whether these SMA-negative cells also lack the expression of eight additional markers that are supposed to present exclusively or preferentially at ME cells.

\section{Materials and methods Case selection}

Formalin-fixed, paraffin-embedded tissue blocks from female patients with breast lesions were retrieved from files of the Armed Forces Institute of Pathology. Consecutive sections at $4-5 \mu \mathrm{m}$ thickness were cut and placed on

$\mathrm{CK}=$ cytokeratin; $\mathrm{ER}=$ estrogen receptor; $\mathrm{H} \& \mathrm{E}=$ hematoxylin/eosin; $\mathrm{ME}=$ myoepithelial; $\mathrm{SMA}=$ smooth muscle actin; $\mathrm{SM}-\mathrm{MHC}=$ smooth muscle myosin heavy chain; WT-1 = Wilms' tumor-1. 
Table 1

\begin{tabular}{|c|c|c|c|c|}
\hline Antibody & Company & Clone & Titer & Staining pattern \\
\hline Alpha-smooth muscle actin & Novocastra & $\alpha s m-1$ & $1: 50$ & Cytoplasmic \\
\hline Maspin & Novocastra & EAW24 & $1: 25$ & Cytoplasmic and nuclear \\
\hline Calponin & Novacastra & CLAP & $1: 25$ & Cytoplasmic \\
\hline Smooth muscle myosin heavy chain & Dako & SMMS-1 & $1: 100$ & Cytoplasmic \\
\hline Wilms' tumor protein & Cell Marque & $6 \mathrm{~F}-\mathrm{H} 2$ & $1: 10$ & Cytoplasmic \\
\hline CD10 & Novocastra & $56 \mathrm{C} 6$ & $1: 80$ & Cytoplasmic \\
\hline Cytokeratin 5 & Novocastra & XM26 & $1: 100$ & Cytoplasmic \\
\hline Cytokeratin 14 & Novocastra & LL002 & $1: 20$ & Cytoplasmic \\
\hline Cytokeratin 17 & Novocastra & E3 & $1: 20$ & Cytoplasmic \\
\hline
\end{tabular}

positively charged microscopic slides. A total of 175 cases with distinct ME cells, defined as a continuous layer of spindle- or cuboid-shaped cells that overlie the basement membrane and encircle epithelial cells, were selected for this study. Among the 175 cases, all contained non-invasive lesions, including ductal and lobular carcinoma in situ and sclerosing adenosis, and a few cases had invasive components.

\section{Markers and reagents}

Nine antibodies reported to present exclusively or preferentially at ME cells were selected for this study [5-25] (Table 1); these included antibodies against SMA, smooth muscle myosin heavy chain (SM-MHC), CD10, calponin, protease inhibitor 5 (maspin), Wilms' tumor-1 (WT-1), and cytokeratins 5, 14, and 17 (CK5, CK4, and CK17). Other reagents, including the secondary antibody, detection kits, and chromogen kits, were purchased from Vector Laboratories, Inc (Burlingame, CA). Digestion enzymes recommended for antigen retrieval were bought from Sigma (St Louis, MO). A microwave oven and pressure cooker designated for antigen retrieval, along with retrieval solutions, were purchased from Biocare Medical (Walnut Creek, $\mathrm{CA})$.

\section{Immunohistochemical staining}

A preliminary study was performed to optimize the immunostaining condition for all antibodies selected. First, each of the nine antibodies was tested strictly in accordance with the manufacturer's recommended protocol, including the methods of antigen retrieval and the length of the primary antibody incubation time. Then, each antibody was tested with our published protocol, which involves an overnight incubation of deparaffinized sections at $70^{\circ} \mathrm{C}$ in the retrieval solution and an incubation for 3-4 hours or overnight of the primary antibody at about protocol and the manufacturer's recommended protocols were compared for specificity and sensitivity. As our protocol consistently yielded stronger and more distinct staining for all the antibodies, the final staining for all the 175 cases with SMA and a double immunostaining with additional markers in selected cases (see below) were performed with our published protocol [26].

\section{Double immunohistochemical staining}

All H\&E-stained and immunostained sections were reviewed independently by at least two investigators. All ducts lined by at least 50 epithelial cells were examined, and three cases were found to contain ducts that displayed morphologically distinct $\mathrm{ME}$ cell layers in H\&Estained sections, but ME cells in at least one-third of the layer or the entire layer were devoid of SMA staining. Eight consecutive sections from each of the three selected cases were used for a double immunostaining with our published protocols $[26,27]$. In brief, all eight sections were first immunostained for SMA with a black chromogen. Each section was then stained for one of the eight additional ME markers with a red chromogen. The same ducts with SMA-negative ME cells were examined for the expression of other markers. In addition, sections from all three cases were immunostained for estrogen receptor (ER) and CK8 to exclude the possibility that these SMAnegative cells might be epithelial in nature.

\section{Results and discussion}

Results showed that all three cases spanned a morphologic spectrum ranging from columnar cell hyperplasia to ductal carcinoma in situ. Case 1 (columnar cell hyperplasia) contained two ducts of interest lined by about 500 epithelial cells surrounded by morphologically distinct ME cell layers on the H\&E-stained section (Fig. 1a). The ME cells in about two-thirds of the ME layer showed distinct and strong SMA immunostaining, whereas the cells 


\section{Figure 1}

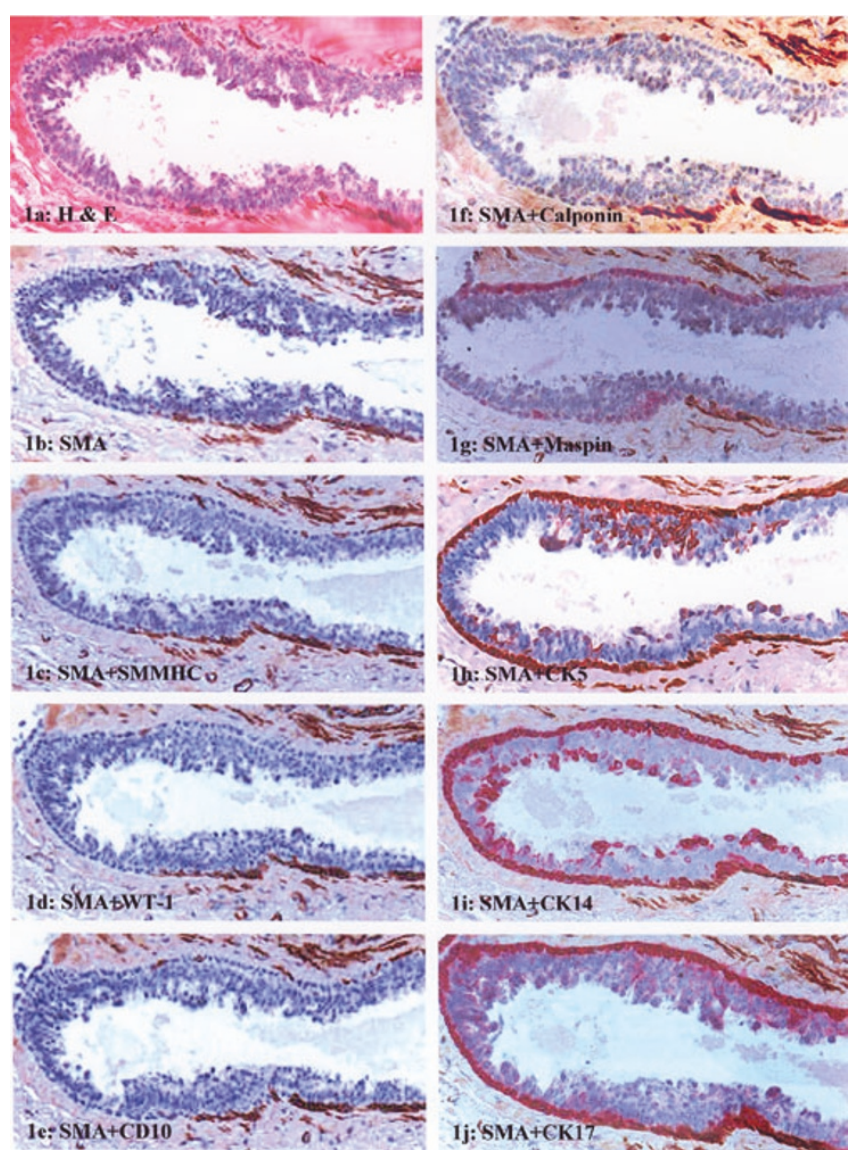

Immunostaining pattern of ME cells in columnar hyperplasia (case 1). (a) H\&E staining; (b) immunostaining for SMA; (c-f) double immunostaining of SMA with SM-MHC, WT-1, CD10, and calponin, respectively, and the segment of the ME layer is negative for all antibodies; (g-j) double immunostaining of SMA with maspin, CK5, CK14, and CK17, respectively, and the segment of the ME layer is positive for all antibodies.

in about one-third of the layer were devoid of SMA immunostaining (Fig. 1b). The SMA-positive and SMAnegative cells were morphologically indistinguishable on H\&E-stained sections. In double immunostained sections, these SMA-negative cells were also negative for SMMHC, WT-1, CD10, and calponin (Fig. 1c-f). However, these SMA-negative cells were positive for maspin, CK5, CK14, and CK17 (Fig. 1g-j).

Cases 2 and 3 contained ductal carcinoma in situ, of intermediate grade and low grade, respectively. The ducts were surrounded by morphologically distinct $M E$ cell layers in H\&E-stained sections (Fig. 2a). These ME cell layers were attenuated, consisting of elongated spindle cells with dark and compressed nuclei. The entire ME cell layer was devoid of SMA immunostaining (Fig. 2b). In double immunostained sections, these SMA-negative cells were also devoid of distinct immunostaining for any of the additional eight markers (Fig. 2c-f).

The SMA-negative cells in all three cases showed distinct negativity to ER and CK8, in sharp contrast with the overlying epithelial cells that showed strong ER and CK8 positivities (data not shown). The distribution of these SMA-negative ME cells seemed to be independent of the ductal size, length, and architecture.

Our findings are consistent with those of a recent study showing that a vast majority of the ME cells in both normal and ductal carcinoma in situ displayed distinct immunostaining to $\mathrm{p} 63, \mathrm{SM}-\mathrm{MHC}$, and calponin, whereas a single or a cluster of a few ME cells in some ducts failed to show immunoreactivity to all these three markers [28]. However, our study differs from this study [28] and previous studies $[3,4]$ in four aspects: first, the SMA-negative cells were segmented, accounting for at least one-third or all of the ME cells in involved ducts; second, we tested for more ME cell markers; third, the SMA-negative cells assessed were morphologically similar to their adjacent SMA-positive neighbors on H\&E-stained sections; fourth, our focus is directed toward the elucidation of the detailed immunohistochemical profile of these SMA-negative cells identified in 3 of 175 examined cases. The distribution of different ME markers among normal, benign, and malignant breast lesions in the remaining cases will be presented separately. In our study, p63 was replaced with WT-1 for three main reasons: first, p63 is a nuclear protein, which is not easily identifiable in attenuated or compressed ME cells; second, previous studies have shown that this protein is also expressed in ME-cellderived neoplasms and tumors with squamous cell differentiation [29]; third, our preliminary study had showed that WT-1 had the same subcellular localization but seemed to be more specific for ME cells, compared with p63 [12].

The mechanism of the loss of myoepithelial markers in some of the ME cells is unknown, but could result from the dynamic and reciprocal interactions between epithelial and ME cells. It has been documented that a variety of proteolytic enzymes produced by malignant epithelial cells could have substantial impacts on the physical integrity or functions of the subjacent ME cells and the basement membrane [30-32]. In contrast, ME cells could influence the biological behavior of subjacent epithelial cells. Our recent studies have revealed the co-localization of maspin and WT-1 exclusively in mammary ME cells [12]. In a vast majority of cases, the expression of these two proteins decreases linearly with tumor progression, and the loss of these proteins or focal disruptions in the ME cell layers leads to a significantly higher cell proliferation in the subjacent epithelial cells $[12,33]$. In addition, these changes in ME cells could result from effects of certain chemical compounds. 


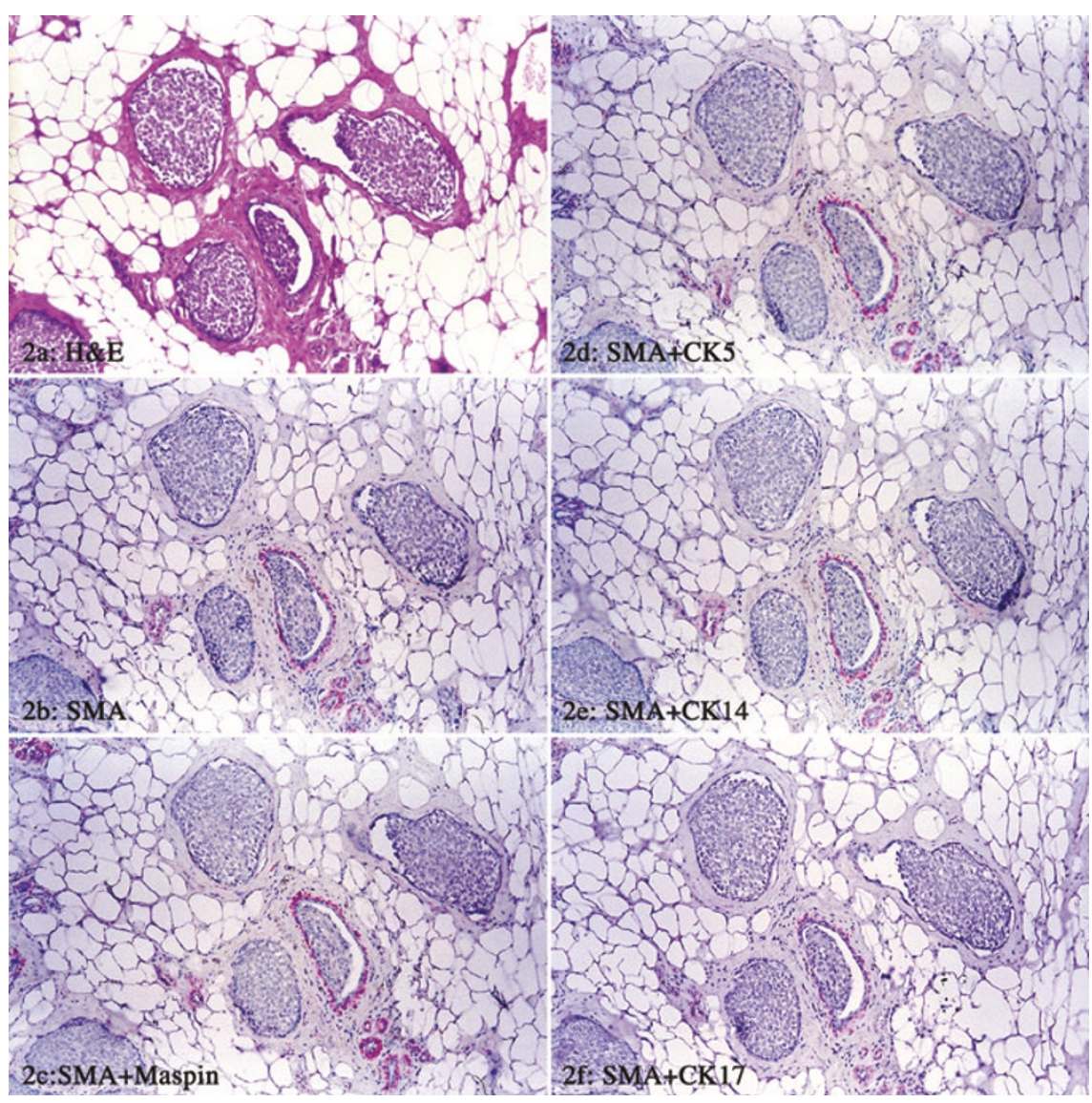

Immunostaining pattern of ME cells in ductal carcinoma in situ (case 2). (a) H\&E staining; (b) immunostaining for SMA; (c-f) double immunostaining of SMA with maspin, CK5, CK14, and CK17, respectively, and the entire ME cell layer is negative for these antibodies in some ducts and is also negative for SM-MHC, WT-1, CD10, and calponin (not shown).

It has been reported that the exposure to lambdacarrageenan could specifically result in filament disassembly and loss of ME cells [34]. In contrast, exposure to oxytocin could substantially enhance ME cell differentiation and proliferation in mouse breasts [35]. In addition, these SMA-negative ME cells might be newly formed through stem-cell-mediated proliferation and are in the transition to a terminally differentiated status. Our previous studies on animal models have shown that intercalated duct cells in adult rat submandibular glands are the common progenitor for both the acinar and granular duct cells $[27,36]$. A recent study in human breast has revealed that CK5-positive cells are capable of giving rise to both glandular and ME cell lineages [21]. In both cases the intermediate cells showed an unusual immunostaining pattern for several proteins $[21,36]$.

The total loss of all nine ME cell immunophenotypic markers suggests that these ME cells have genetic and biochemical properties differing from their SMA-positive changes in ME cells are unknown. However, given that the disruption of the ME cell layer and basement membrane is an absolute prerequisite for tumor invasion and metastasis, these alterations in ME cells might affect the biological behavior of the epithelial cells, making them prone to progression. Our assumption is in agreement with our previous findings, which have revealed that focal disruptions of ME cell layers could lead to a significantly higher proliferation rate in subjacent epithelial cells $[12,33]$. Our assumption is also supported by a recent study showing that normal and tumor-derived ME cells differ substantially in their ability to interact with luminal breast epithelial cells for polarity and basement membrane deposition [37]. Further studies are currently in progress to elucidate the biological behavior and genetic profile of epithelial cells immediately subjacent to these SMA-negative ME cells.

\section{Conclusions}

A subset of morphologically identifiable ME cells lacks the expression of nine corresponding immunophenotypic markers, suggesting that, like the epithelial cells, ME cells 
might also be subject to different normal and pathological alterations, and that alterations in ME cells might significantly affect the functions and biological behavior of the adjacent epithelial cells.

\section{Competing interests}

None declared.

\section{Acknowledgments}

The authors are indebted to Mr Doug Landry and James A Nola of the AFIP exhibition section and Mr Kenneth J Vrtacnik of the AFIP Photography Lab for their assistance in preparation of the figures. This study was supported in part by grants DAMD17-01-1-0129 and DAMD1701-1-0130 from Congressionally Directed Medical Research Programs to YM. The opinions and assertions contained herein are the private viewpoints of the authors and do not reflect the official views of The Department of Defense or The Army.

\section{References}

1. Sternlight MD, Barsky SH: The myoepithelial defense: a host defense against cancer. Med Hypotheses 1997, 48:37-46.

2. Masood S, Sim SJ, Lu L: Immunohistochemical differentiation of atypical hyperplasia vs. carcinoma in situ of the breast. Cancer Detect Prev 1992, 16:225-235.

3. Bose S, Derosa CM, Ozzello L: Immunostaining of type IV collage and smooth muscle actin as an aid in the diagnosis of breast lesions. Breast J 1999, 5:194-201.

4. Joshi MG, Lee AK, Pedersen CA, Schnitt S, Camus MG, Hughes $K S$ : The role of immunocytochemical markers in the differential diagnosis of proliferative and neoplastic lesions of the breast. Mod Pathol 1996, 9:57-62.

5. Blacque $\mathrm{OE}$, Worrall DM: Evidence of a direct interaction between the tumorsuppressor serpin, maspin, and types I and III collagen. J Biol Chem 2002, 277:10783-10788.

6. Maass N, Hojo T, Zhang M, Sager R, Jonat W, Nagasaki K: Maspin - a novel protease inhibitor with tumor suppressing activity in breast cancer. Acta Oncol 2000, 39:931-934.

7. Zou Z, Zhang W, Young D, Gleave MG, Rennie P, Connell T, Connelly R, Moul J, Srivastava S, Sesterhenn I: Maspin expression profile in human prostate cancer $(\mathrm{CaP})$ and in vitro induction of Maspin expression by androgen ablation. Clin Cancer Res 2002, 8:1172-1177.

8. Reis-Filho JS, Milanezi F, Silva P, Schmitt FC: Maspin expression in myoepithelial tumors of the breast. Pathol Res Pract 2001, 197:817-821.

9. Scharnhorst V, van der Eb AJ, Jochemsen AG: WT1 proteins: functions in growth and differentiation. Gene 2001, 273:141161.

10. Fabre A, McCabb AH, O'Shea D, Broderick D, Keating G, Tobin B, Gorey T, Dervan PA: Loss of heterozygosity of the Wilms' tumor suppressor gene (WT-1) in in-situ and invasive breast carcinoma. Hum Pathol 1999, 30:661-665.

11. Zapata-Benavides P, Tuna M, Lopez-Berestein G, Tari AM: Downregulation of Wilms' tumor 1 protein inhibits breast cancer proliferation. Biochem Biophys Res Commun 2002, 295:784790.

12. Man YG, Vang RS, Saenger JS, Strauss B, Bratthauer GL, Chen PY, Tavassoli FA: Co-expression of maspin and Wilms' tumor 1 proteins in mammary myoepithelial cells - implication for tumor progression and invasion. In Proceedings of Department of Defense Breast Cancer Research Program Meeting: September 25-28, 2002; Orlando, Florida. Edited by US Army Medical Research and Material Command. Fort Detrick, Maryland, USA: Office of the Commanding General; 2002: vol 19,16.

13. Mahendran R, Mcllhinney R, O'Hare M, Monaghan P, Gusterson $B$ : Expression of the common acute lymphoblastic leukaemia antigen (CALLA) in the human breast. Mol Cell Probes 1989, 3:39-44.

14. Iwaya K, Ogawa H, Izumi M, Kuroda M, Mukai K: Stromal expression of CD10 in invasive breast carcinoma: a new predictor of clinical outcome. Virchows Arch 2002, 440:589-593.

15. Moritani S, Kushima R, Sugihara H, Bamba M, Kobayashi T, Hattori T: Availability of CD10 immunohistochemistry as a marker of breast myoepithelial cells on paraffin sections. Mod Pathol 2002, 15:397-405.

16. Yaziji $\mathrm{H}$, Gown AM, Sneige N: Detection of stromal invasion in breast cancer: the myoepithelial markers. Adv Anat Pathol 2000, 7:100-109.

17. Damiani S, Ludvikova M, Tomasic G, Bianchi S, Gown AM, Eusebi $\mathrm{V}$ : Myoepithelial cells and basal lamina in poorly differentiated in situ duct carcinoma of the breast. An immunocytochemical study. Virchows Arch 1999, 434:227-234.

18. Dabbs DJ, Gown AM: Distribution of calponin and smooth muscle myosin heavy chain in fine-needle aspiration biopsies of the breast. Diag Cytopathol 1999, 20:203-207.

19. Ohyabu I, Takasaki T, Akiba S, Nomura S, Enokizono N, Sagara Y, Hiroi J, Nagai R, Yoshida H: Immunohistochemical studies on expression of human vascular smooth muscle myosin heavy chain isoforms in normal mammary glands, benign mammary disorders and mammary carcinomas. Pathol Int 1998, 48:433439.

20. Moll R, Franke WW, Schiller DL, Geiger B, Krepler R: The catalog of human cytokeratins: patterns of expression in normal epithelia, tumors and cultured cells. Cell 1982, 31:1124.

21. Bocker W, Moll R, Poremba C, Holland R, van Diest PJ, Dervan $P$, Burger H, Wai D, Diallo RI, Brandt B, Herbst H, Schmidt A, Lerch MM, Buchwallow IB: Common adult stem cells in the human breast give rise to glandular and myoepithelial cell lineages: a new cell biological concept. Lab Invest 2002, 82:737-746.

22. Bocker W, Moll R, Dervan $P$, Buerger H, Poremba C, Diallo R, Herbst $H$, Schmidt A, Lerch MM, Buchwallow IB: Usual ductal hyperplasia of the breast is a committed stem (progenitor) cell lesion distinct from atypical ductal hyperplasia and ductal carcinoma in situ. J Pathol 2002, 198:458-467.

23. Wetzels RH, Kuijpers HJ, Lane EB, Leigh IM, Troyanovsky SM, Holland R, Van Haelst UJ, Ramaekers FC: Basal cell-specific and hyperproliferation-related keratins in human breast cancer. Am J Pathol 1991, 138:751-763.

24. Wetzels RH, Holland R, Van Haelst UJ, Lane EB, Leigh IM, Ramaekers FC: Detection of basement membrane components and basal cell keratin 14 in noninvasive and invasive carcinomas of the breast. Am J Pathol 1989, 134:571-579.

25. McGowan KM, Coulumbe PA: Onset of keratin 17 expression coincides with the definition of major epithelial lineages during skin development. J Cell Biol 1998, 143:469-486.

26. Man YG, Tavassoli FA: A simple epitope retrieval method without the use of microwave oven or enzyme digestion. Appl Immunohistochem 1996, 4:139-141.

27. Man YG, Ball WD, Culp AJ, Hand AR, Moreira JE: Persistence of a perinatal cellular phenotype in the ducts of adult glands. $J$ Histochem Cytochem 1995, 43:1203-1215.

28. Werling RW, Hwang $\mathrm{H}$, Yaziji $\mathrm{H}$, Gown AM: Immunohistochemical distinction of invasive from noninvasive breast lesions: a comparative study of p63 versus calponin and smooth muscle myosin heavy chain. Am J Surg Pathol 2003, 27:82-90.

29. Barbareschi M, Pecciarini L, Cangi MG, Macri E, Rizzo A, Viale G, Doglioni C: p63, a p53 homologue, is a selective nuclear marker of myoepithelial cells of the human breast. Am J Surg Pathol. 2001, 25:1054-1060.

30. Goldfarb RH, Liotta LA: Proteolytic enzymes in cancer invasion and metastasis. Semin Thromb Hemost 1986, 12:294-307.

31. Mignatti $P$, Robbins $E$, Rifkin DB: Tumor invasion through the human amniotic membrane: requirement for a proteinase cascade. Cell 1986, 47:487-498.

32. Wang F, Weaver VM, Petersen OW, Larabell CA, Dedhar S, Briand $\mathrm{P}$, Lupu R, Bissell MJ: Reciprocal interactions between $\beta 1$-integrin and epidermal growth factor receptor in threedimensional basement membrane breast cultures: a different perspective in epithelial biology. Proc Natl Acad Sci USA 1998, 95:14821-14826.

33. Man YG, Saenger JS, Strauss B, Vang RS, Bratthauer GL, Chen PY, Tavassoli FA: Focal alterations of p27 expression and subjacent myoepithelial cell layer disruptions are correlated events in ER- ductal intraepithelial neoplasia. In Proceedings of Department of Defense Breast Cancer Research Program Meeting: September 25-28, 2002; Orlando, Florida. Edited by US Army Medical Research and Material Command. Fort Detrick, Maryland, USA: Office of the Commanding General; 2002: vol 1 9,14 . 
34. Tobacman JK: Filament disassembly and loss of mammary myoepithelial cells after exposure to lambda-carrageenan. Cancer Res 1997, 57:2823-2826.

35. Sapino A, Macri L, Tonda L, Bussolati G: Oxytocin enhances myoepithelial cell differentiation and proliferation in the mouse mammary gland. Endocrinology 1993, 133:838-842.

36. Man YG, Ball WD, Marchetti L, Hand AR: Contributions of intercalated duct cells to the normal parenchyma of submandibular glands of adult rats. Anat Rec 2001, 263:202-214.

37. Gudjonsson T, Ronnov-Jessen L, Villadsen R, Rank F, Bissell MJ, Petersen OW: Normal and tumor-derived myoepithelial cells differ in their ability to interact with luminal breast epithelial cells for polarity and basement membrane deposition. J Cell Sci 2002, 115:39-50.

\section{Correspondence}

Yan-Gao Man MD PhD, Department of Gynecologic and Breast Pathology, Armed Forces Institute of Pathology, 6825 16th Street, NW, Washington, DC 20306, USA. Tel: +1 202782 1612; fax: +1 202

782 -3939; e-mail: man@afip.osd.mil 